\title{
Expression of a microbial serine proteinase inhibitor gene enhances the tobacco defense against oomycete pathogens
}

\author{
Yussuan Silva a,b,1, Roxana Portieles ${ }^{\mathrm{a}, 1}$, Merardo Pujol ${ }^{\mathrm{a}}$, Ryohei Terauchi ${ }^{\mathrm{c}}$, \\ Hideo Matsumura $^{\mathrm{d}}$, Mario Serrano ${ }^{\mathrm{e}}$, Orlando Borrás-Hidalgo ${ }^{\mathrm{a}, *}$ \\ ${ }^{a}$ Center for Genetic Engineering and Biotechnology, P.O. Box 6162, Havana 10600, Cuba \\ ${ }^{\mathrm{b}}$ Tobacco Research Institute, Carretera de Tumbadero 8, P.O. Box 6063, San Antonio de los Baños, Havana, Cuba \\ ${ }^{\mathrm{c}}$ Iwate Biotechnology Research Center, Kitakami, Iwate 024-0003, Japan \\ d Gene Research Center, Shinshu University, Ueda 386-8567, Japan \\ ${ }^{\mathrm{e}}$ Department of Biology, University of Fribourg, Fribourg, Switzerland
}

\begin{abstract}
In order to identify Nicotiana megalosiphon genes for novel inhibitors of microbial serine proteinase involved in resistance to the oomycete Phytophthora parasitica var. nicotianae, SuperSAGE technology combined with next-generation sequencing were used to generate libraries in order to identify transcripts that are differentially up-regulated. We identified a N. megalosiphon inhibitor of microbial serine proteinase gene (NmIMSP) rapidly induced during the interaction. Silencing of NmIMSP gene was found to compromise the resistance of $N$. megalosiphon to $P$. parasitica var. nicotianae. Herewith, the transient expression of NmIMSP gene in a susceptible genotype conferred high level of resistance to $P$. parasitica var. nicotianae and Peronospora hyoscyami f. sp. tabacina. This is the first evidence of this inhibitor of microbial serine proteinase as a positive regulator of defense response against oomycete.
\end{abstract}

\section{Introduction}

Black shank, caused by Phytophthora parasitica var. nicotianae, constitutes one of the most important tobacco diseases [4]. The pathogen infects roots, stems, and leaves, resulting in root necrosis, wilting, chlorosis, stem lesions, stunting, and plant death. The annual losses from black shank were estimated between 1 and $3 \%$ in tobacco production area [4]. Black shank is managed by using an integrated approach that includes cultural practices, fungicide applications, and resistant cultivars. The most effective method for managing the disease is the use of resistant cultivars [4]. However, the resistance source is limited into the germplasm. Nicotiana megalosiphon is a wild tobacco species that is generally used as a parent in genetic tobacco breeding programs [3]. For example, $N$. megalosiphon has been shown to be highly resistant to $P$. parasitica var. nicotianae and Peronospora hyoscyami f. sp. tabacina [3,4].

Plant defense against pathogens is a complex process that involves the activation of different signaling pathways leading to the

\footnotetext{
* Corresponding author. Tel.: +53 72716022.

E-mail address: orlando.borras@cigb.edu.cu (O. Borrás-Hidalgo).

1 These authors contributed equally.
}

overexpression of target genes with defense properties. One of the main groups of proteins induced after plant-pathogen interaction corresponds to the protease inhibitors. These proteins are located in seeds or tubers and are induced in vegetative organs such as leaves or roots. Two functions have been related to these proteins: i) regulation of endogenous plant proteases; and ii) inhibition of exogenous proteases from arthropod pests and plant pathogenic microorganisms [26].

The implication of protease inhibitors on fungal and bacterial growth inhibition has been previously reported $[11,16,17,21]$. Increased levels of trypsin and chymotrypsin inhibitors correlated with the plants resistance against different pathogens [15,26]. This process was first found in tomato plants infected with Phytophthora infestans [38], in which increased levels of trypsin and chymotrypsin inhibitors were correlated with the plant's resistance to this pathogen. Previous studies showed that potato tubers accumulate inhibitors of serine proteinases in response to $P$. infestans infection $[35,36]$. They play an important role in the protection of plant tissues from pathogen attack by inhibiting nutrition uptake by pathogens, i.e. protease inhibitors are considered to inhibit the growth of pathogen microorganisms by anti-feeding mechanism [37].

Meanwhile, tobacco mosaic virus-infected leaves produce a serine proteinase inhibitor that has evolved specificity for inhibiting 
microbial proteinases. This protein was accumulated during the hypersensitive reaction of tobacco to Tobacco Mosaic Virus. This inhibitor was highly active against several serine endoproteinases of fungal and bacterial origins [9]. Conversely, some serine proteinases inhibitor produced by pathogens interferes with the defense response. The typical Kazal domains are ubiquitous in serine proteinase inhibitor of plant pathogenic oomycetes. Two of the Kazal like inhibitors namely EP11 and EP110 of the potato late-blight fungus $P$. infestans target the defense-related protease P69B of the host plant tomato [32].

High-Throughput (HT)-SuperSAGE technology combined with next-generation sequencing is a method of digital gene expression profiling that allows isolation of 26-bp tag fragments from expressed transcripts. During the protocol, index sequences are employed to discriminate tags from different samples. Such index allows analyzing digital tags from transcriptomes of many samples in a single sequencing run by simply pooling the libraries. The major advantage of HT-SuperSAGE over other similar techniques is that 26-bp tag sequences can be isolated from each transcript, which is so far the longest tag sequence obtained from a defined position of transcripts. Additionally, this technology provided highly sensitive, reproducible and accurate digital gene expression data [22].

To gain insight in the molecular components that are responsible for the establishment of the resistance of $N$. megalosiphon to tobacco black shank, an HT-SuperSAGE in combination with next generation sequencing was used to identify novel inhibitors of microbial serine proteinase during the N. megalosiphon - P. parasitica var. nicotianae interaction. Subsequently, employing of virus-induced gene silencing (VIGS) and gain function approach in Nicotiana species demonstrated the contribution of an inhibitor of microbial serine proteinase gene in the black shank resistance in N. megalosiphon.

\section{Materials and methods}

\subsection{Plant material and inoculation procedure}

The resistant $N$. megalosiphon and susceptible Nicotiana benthamiana species (seeds provided by the Tobacco Research Institute, Cuba) were used in the experiments. Field-single isolates from P. parasitica var. nicotianae race 0 (PpnIIT23) and P. hyoscyami f. sp. tabacina (PhtIIT324) (provided by the Cuban Research Institute of Plant Health, Havana, Cuba) were used for all inoculations throughout this study and isolated from naturally infected tobacco plants in Havana fields. The isolates from P. parasitica var. nicotianae race 0 and $P$. hyoscyami f. sp. tabacina were identified and classified through sequencing the ITS region that matched the sequence of the GenBank isolate with accession number DQ059571.1 and DQ067898.1, respectively. The inoculum and the protocol for inoculation under greenhouse condition were prepared as described previously $[3,6]$. Data related with the evaluation of the disease resistance were analyzed by one-way analysis of variance procedures of GraphPad Prism 5.0 (GraphPad Software, Inc, California). Significant difference among means was determined by Tukey's Multiple Comparison Test least significant difference mean separation at $P<0.05$.

\subsection{Construction of SuperSAGE libraries}

Two SuperSAGE libraries to generate transcripts that were differentially induced during the $P$. parasitica var. nicotianae-resistant tobacco species N. megalosiphon were developed. Specifically, we focus on inhibitor genes of microbial serine proteinases that were induced during the interaction. Leaves, stems and roots materials were collected from inoculated $N$. megalosiphon plants (6week-old) at 1, 3 and 7 days after inoculation of $P$. parasitica var. nicotianae and pooled before RNA extraction (experimental sample library). As control, the same plant materials from mock-inoculated plants harvested at the same time points were used (control library).

Total RNA was extracted using the RNeasy kit (Qiagen, Valencia, CA), including an on-column DNAse treatment (Qiagen, Valencia, CA) according to manufacturer's instructions. The Super-SAGE library was constructed according to Matsumura et al. [22]. Doublestranded cDNA was synthesized using the biotinylated adapteroligodT primer (5'-bio-CTGATCTAGAGGTACCGGATCCCAGCAG $(T)^{17}$ $3^{\prime}$ ). Purified cDNA was digested with anchoring enzymes NlaIII, resulting fragments were bound to streptavidin-coated beads (Dynabeads streptavidin M-270), and non-biotinylated cDNA fragments were removed by washing. Adapter-2 (5'-CAAGCAGAAGACGGCATACGATCTAACGATGTACGCAGCAGCATG- $3^{\prime}$ and 5'-CTGCTGCGTACATCGTTAGATCGTATGCCGTCTTCTGCTTG-amino-3') was ligated to cDNA fragments on the beads and after washing digested with EcoP15I. EcoP15I-digested and released fragments (adapter-2- tags) were ligated to adapters-1 (5'-ACAGGTTCAGAGTTCTACAGTCCG ACGATCXXXX-3' and $5^{\prime}$ NNXXXXGATCGTCGGACTGTAGAACTCTGAA CCTGT-amino-3'; XXXX encodes variable index sequences) with defined index sequences for sample identification. Tags sandwiched between two adapters were amplified by PCR using Phusion High polymerase and GEX primers (5'-AATGATACGGCGACCACCGACAGGTTCAGAGTTCTACAGTCCGA- $3^{\prime}$ and 5'-CAAGCAGAAGACGGCATACGA-3'). The PCR reaction consisted of $98^{\circ} \mathrm{C}$ for $1 \mathrm{~min}, 3-10$ cycles at $98{ }^{\circ} \mathrm{C}$ for $30 \mathrm{~s}$, and $60{ }^{\circ} \mathrm{C}$ for $30 \mathrm{~s}$. Eight tubes from this PCR amplification (each $15 \mu \mathrm{l}$ ) were pooled and concentrated PCR products using MinElute reaction purification kit (Qiagen, Valencia, CA) were run on an $8 \%$ non-denaturing polyacrylamide gel. After staining with SYBR green (Takara Bio), the band at 123-125bp was cut out from the gel, and DNA purified after its elution from the gel pieces. The PCR product from each sample was analyzed on an Agilent Bioanalyzer 2100. Equal concentrations of PCR products from the samples were mixed and applied to Illumina Genome Analyzer II sequencing. Purified and mixed PCR products were applied to cluster formation on the flow cell of the Illumina Genome Analyzer II. Sequencing reactions used GEX (DpnII) primer following the instructions of the manufacturer. For each library, the tags were extracted from the sequences using the GXP-Tag sorter software provided by GenX Pro GmbH, Frankfurt am Main, Germany.

\subsection{Identification and functional annotation of differentially expressed tags}

Perl scripts were used to determinate the unique sequences from both libraries and singleton removal. The unique sequence was considered a singleton if it was detected only once in the combined libraries. Statistically significant changes in tag copy number between the control and experimental sample libraries were analyzed by calculating a probability $P$-value. For fold-change (FC) calculations the libraries were normalized to 100,000 tags and the FC for each tag was calculated by dividing the number of tags in the experimental sample library by the number of tags in the control library. Differentially expressed tags considered in this study were those having an FC equal or greater than 2.5 (overexpressed tags). Tags identification was performed by running Blastn against the database from Nicotiana tabacum EST sequences [1]. Evalue scores below $10^{-5}$ were considered as significant and were used to indicate homology between tobacco sequences and database sequences. The task parameter was set to 'blastn-short' in order to guarantee the optimal Blast functioning for short sequences searches. Blast2GO software was used to find UniTags functional annotation. The differentially expressed UniTags related with inhibitors of microbial serine proteinase genes were selected. 
To further confirm the SuperSAGE results, RT-PCR was carried out to compare the expression of identified inhibitors of microbial serine proteinase genes. For this purpose, the 26-bp tag sequences obtained by SuperSAGE were directly used as 3'-RACE PCR primers to amplify the regions between the tag and poly-A tail. Using the same RNA, cDNA was synthesized separately using an anchored oligodT primer (5'-biotin-CTGATCTAGAGGTACCGGATCCCAGCAG $\left.(T)^{17}-3^{\prime}\right)$. For $3^{\prime}$-RACE PCR, 26-bp primers corresponding to the SuperSAGE tags were used in combination with the primer (polyT anc: $5^{\prime}$-GGCCACGCGTCGACTAGTAC $(\mathrm{T})^{17}-3^{\prime}$ ) complementary to the cDNA ends. The primers used in the experiments are listed in the Supplementary Table 1. After amplification, products were separated in $1.5 \%$ preparative agarose gels. Bands corresponding to unequivocal amplicons were excised, and DNA extracted with Qiaquick cleanup columns (QIAGEN, Hilden, Germany). The PCR products were sequenced to confirm the identity via $A B I$ prism multi-color fluorescence-based DNA analysis system (APPLIED BIOSYSTEMS, Foster City CA, USA).

\subsection{Real-time PCR analyses}

The subset of differentially expressed UniTags was selected for further analysis based on strong and significant changes as revealed by SuperSAGE and 3'-RACE-PCR. The selected UniTags were used to study the kinetic of mRNA induction in different time points and organs. In an independent experiment, total RNA was extracted from $N$. megalosiphon plants in different organs (leaves, stem and roots) and time points after inoculation with $P$. parasitica var. nicotianae as described in a previous section. The cDNA was synthesized using the adapter - oligodT primer (5'-CTGATCTAGAGGTACCGGATCC CAGCAG(T $\left.)^{17}-3^{\prime}\right)$ using the SuperScript III reverse transcriptase kit (Invitrogen, Carlsbad, CA). The 26-bp SuperSAGE tag sequences validated were used as $3^{\prime}$-RACE RT-PCR primers in combination with the primer (polyT anc: 5'-GGCCACGCGTCGACTAGTAC $(\mathrm{T})^{17}-3^{\prime}$ ) complementary to the cDNA ends to amplify the regions between tags and poly-A tail for the selected NmIMSP. The primers used in the experiments are listed in the Supplementary Table 1. Quantitative real-time PCR was conducted using a Rotor - Gene 3000 PCR machine (Corbett, Australia) with the QuantiTect SYBR Green PCR Kit (Qiagen, Valencia, CA). Real-time PCR conditions were as follows: an initial $95^{\circ} \mathrm{C}$ denaturation step for $15 \mathrm{~min}$ followed by denaturation for $15 \mathrm{~s}$ at $95^{\circ} \mathrm{C}$, annealing for $30 \mathrm{~s}$ at $60^{\circ} \mathrm{C}$, and extension for $30 \mathrm{~s}$ at $72{ }^{\circ} \mathrm{C}$ for 40 cycles and analyzed on the Rotor - Gene 3000 software (Corbett, Australia). Five replicates for each sample were used for real-time PCR analysis and the experiment was repeated two times.

\subsection{Virus-induced gene silencing (VIGS) assay}

To test whether the cDNA encoding the NmIMSP indeed contribute to the disease resistant phenotype of $N$. megalosiphon, it was attempted to knock down their induction in N. megalosiphon using virus-induced gene silencing (VIGS). To this end, construct was designed and inoculated on N. megalosiphon plants. For VIGS analysis in $P$. parasitica var. nicotianae-resistant $N$. megalosiphon plants, tobacco rattle virus (TRV) vectors were used [25]. The phytoene desaturase gene (PDS, used as a control to monitor silencing efficiency in N. megalosiphon) and NmIMSP cDNA fragments were cloned using the SmaI sites of pTV00 to form pTV:PDS and pTV:NmIMSP, respectively. The primers used in the experiments are listed in the Supplementary Table 1 . The infection of N. megalosiphon with TRV was carried out using a total of 50 plants per construct using the protocol as described [25]. After TRV inoculation, transcript accumulation was monitored by real time PCR analysis according to the above described procedure. Ten days post inoculation with the TRV constructs, the plants were inoculated with $P$. parasitica var. nicotianae and subsequently the development of symptoms was monitored.

\subsection{Transient expression of NmIMSP}

The full-length coding region for NmIMSP gene was obtained according to specifications in the SMART RACE II kit (BD Clontech) and submitted to GenBank (accession number: submitted). The primers used in the experiments are listed in the Supplementary Table 1. The PVX vector (pGR106) $[13,18]$, used in this study was obtained from David Baulcombe (Sainsbury Laboratory, Norwich, UK). PVX::GFP was generated by cloning a PCR fragment amplified from a GFP cDNA template (GenBank accession number U62637) using specific oligonucleotide primers incorporating AscI and NotI restrictions sites respectively for cloning into pGR106. Agrobacterium tumefaciens strain LB4404, carrying the helper plasmid pSoup [12] was transformed with constructs PVX::GFP or PVX::NmIMSP. Agro-infiltration of $N$. benthamiana species with PVX vector was performed as previously described [19]. Total RNA was extracted from $N$. benthamiana agro-infiltrated with the constructs PVX::GFP or PVX::NmIMSP at 15 days post-infiltration using RNeasy kit (Qiagen, Valencia, CA), including an in-column DNAse treatment (Qiagen, Valencia, CA). The cDNA was synthesized using an oligo(dT) primer and the SuperScript III reverse transcriptase kit (Invitrogen, Carlsbad, CA). Quantitative real-time PCR was conducted using a Rotor-Gene 3000 PCR machine (Corbett, Australia) with the QuantiTect SYBR Green PCR Kit (Qiagen, Valencia, CA). Real-time PCR conditions were as follows: an initial $95{ }^{\circ} \mathrm{C}$ denaturation step for $15 \mathrm{~min}$ followed by denaturation for $15 \mathrm{~s}$ at $95^{\circ} \mathrm{C}$, annealing for $30 \mathrm{~s}$ at $60{ }^{\circ} \mathrm{C}$, and extension for $30 \mathrm{~s}$ at $72{ }^{\circ} \mathrm{C}$ for 40 cycles and analyzed on the Rotor-Gene 3000 software (Corbett, Australia). Five replicates for each sample were used for real-time PCR analysis and the experiment was repeated two times. Additionally, transient expression of $6 \mathrm{xHis}$ tag fused to IMSP N-terminus in N. benthamiana was determined. The polyhistidine-tag:IMSP protein was detected via anti-polyhistidine-tag antibodies by western blotting method on root, stem and leaves from $N$. benthamiana (Supplementary Fig. 1).

\section{Results}

\subsection{Generation of SuperSAGE libraries}

The total number of SuperSAGE tags obtained after sequencing the libraries and eliminating i) incomplete reads, ii) twin-ditags, and iii) ditags without complete library-identification DNA linkers was 2,864,417; comprising 1,437,878 tags from the control library and $1,426,539$ from the experimental sample library. These tags represented 726,251 unique sequences $(339,230$ in the control library and 387,021 in the experimental sample library) (Table 1). These tags are referred as UniTags and will be considered for further analysis. Statistically significant changes in tag copy number between the control and experimental sample libraries were analyzed by calculating a probability $(P)$-value (see Materials and Methods). Although small changes in expression levels may have biological

Table 1

Summary of all the analyzed SuperSAGE libraries.

\begin{tabular}{|c|c|c|c|}
\hline Library & Control & $\begin{array}{l}\text { Experimental } \\
\text { sample }\end{array}$ & Total \\
\hline Sequenced tags & $1,437,878$ & $1,426,539$ & $2,864,417$ \\
\hline $\begin{array}{l}\text { Number of unique } \\
\text { transcripts (UniTags) }\end{array}$ & 339,230 & 387,021 & 726,251 \\
\hline Number of non- singletons & 112,577 & 108,166 & 220,743 \\
\hline
\end{tabular}


significance, we focused primarily on genes which showed strong changes in expression levels with arbitrary FC values $\geq 2.5$. Based on the calculated $(P)$-values and using a 95\% confidence level, 21,676 UniTags were identified as differentially expressed after the inoculation of N. megalosiphon with P. parasitica. Among these UniTags, 1301 were differentially up-regulated UniTags.

To obtain gene function categories of the differentially expressed UniTags, gene ontology (GO) annotation was performed by BLASTX (using the corresponding annotated nucleotide sequences as queries) against the non-redundant GenBank and UniProtKB/ TrEMBL protein databases. For this analysis, we used UniTags that showed a maximum of 2 mismatches (24/26) with entries in the GenBank nucleotide database. Of the 1301 differentially expressed UniTags, a total of 9 annotated UniTags corresponded to genes for inhibitors of microbial serine proteinase with an FC values $\geq 2.5$ (Table 2). To further confirm the SuperSAGE results, RT-PCR was carried out to compare the expression of identified inhibitor genes of microbial serine proteinases. The expression changes observed by SuperSAGE were confirmed by 3'-RACE-PCR for 4 genes (for Tag 14613, Tag 78459, Tag 2318, Tag 49066). For the Tag 32716, specific PCR products did not indicate differential expression (Fig. 1A).

Accumulation patterns of mRNAs corresponding to four genes of inhibitors of microbial serine proteinase were consistent between SuperSAGE and 3'-RACE-PCR with an increase after inoculation with $P$. parasitica var. nicotianae. Induction of mRNA corresponding to Tag 14613 was slight. Interestingly, the transcript corresponding to the Tag-49066 exhibited both strong and consistent induction at all time points evaluated during the interaction. The Tag 2318 and Tag 78459 were induced after one day post-inoculation and their expression was down-regulated during 3 and 7 days post-inoculation (Fig. 1B). We therefore selected the gene corresponding to Tag 49066 to evaluate its regulation in leaves, stems and roots at different time points. The expression level of this transcript was higher in leaves compared to that in stems and roots, respectively (Fig. 1C).

The full-length coding region of the gene for the inhibitor of microbial serine proteinase (NmIMSP), as represented by the Tag 49066, was obtained by $3^{\prime}-$ and $5^{\prime}$-RACE. NmIMSP is coding for a 107 amino acids protein. Amino acid sequence comparison showed that the NmIMSP has a high similarity with different representative members of Solanaceae IMSPs. There were few amino acid replacements observed between NmIMSP with Nicotiana IMSPs (Fig. 2A). Additionally, a phylogenetic analysis based on the structural organization of members of Solanaceae IMSPs is shown in Fig. 2B. The phylogenetic analysis showed that the members from Nicotiana IMSPs are closely related (Fig. 2B).

Table 2

List of the UniTags related with genes of inhibitors of microbial serine proteinases.

\begin{tabular}{lccc}
\hline Tag sequence & \multicolumn{2}{l}{ Tag count $^{\mathrm{a}}$} & $\begin{array}{l}\text { Fold } \\
\text { change }\end{array}$ \\
\cline { 2 - 3 } & Control & $\begin{array}{l}\text { Experimental } \\
\text { sample }\end{array}$ & 3.2 \\
\hline $\begin{array}{c}\text { Tag 32716 CATGTATTAAT } \\
\quad \text { CCATTATTGGTGAT }\end{array}$ & 16.5 & 54.2 & 4.7 \\
$\begin{array}{c}\text { Tag 14613 CATGGCCAGA } \\
\text { ACTTATTGGTGTACCA }\end{array}$ & 45.3 & 217.0 & 10.5 \\
$\begin{array}{c}\text { Tag 78459 CATGTCTCAGT } \\
\quad \text { CCGATGGTTGCCAG }\end{array}$ & 4.1 & 43.4 & 16.8 \\
$\begin{array}{c}\text { Tag 2318 CATGTACTCCAT } \\
\quad \text { TGTTTGGCGATAAA }\end{array}$ & 272.3 & 4594.0 & 44.7 \\
$\begin{array}{c}\text { Tag 49066 CATGGAAACGT } \\
\text { TAACCATACAGCTCC }\end{array}$ & 8.2 & 368.9 & \\
\hline
\end{tabular}

a The libraries were normalized to 100,000 tags and the fold change for each tag was calculated by dividing the number of tags in the experimental sample by the number of tags in the control sample.
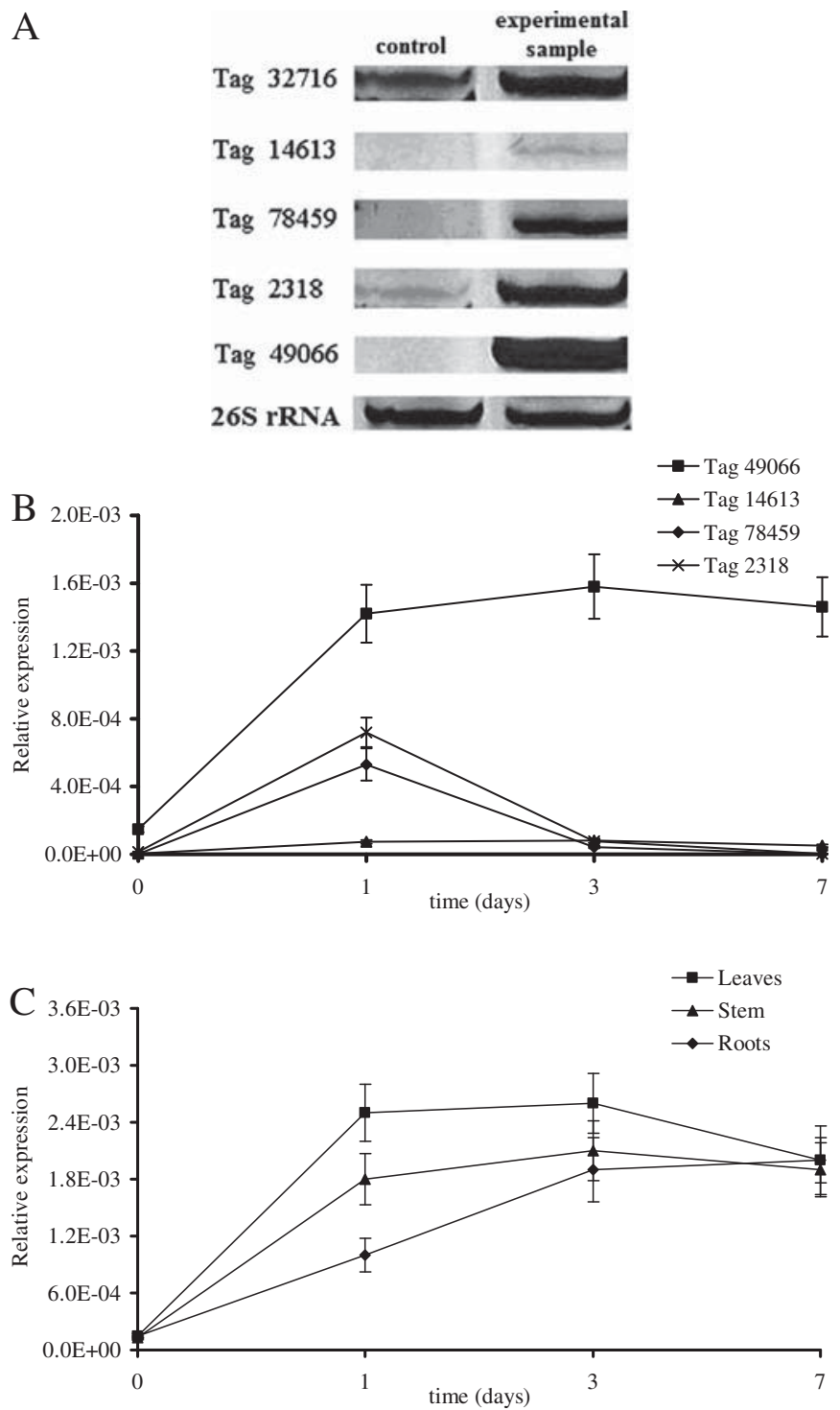

Fig. 1. An inhibitor of microbial serine proteinase (Tag 49066) is highly induced during P. parasitica var. nicotianae - N. megalosiphon interaction. A) 3'-RACE-PCR of the UniTags related with inhibitors of microbial serine proteinase. The 26-bp SuperSAGE tag sequence listed in Supplementary Table 1 was used as 3'-RACE PCR primers to amplify the regions between tags and poly-A tail. The $3^{\prime}$-RACE PCR products were sequenced and annotated by BLAST searches. 3'-RACE-PCR was developed with a pool of leaves, stem and roots at different time-point from mock-inoculated and inoculated $N$. megalosiphon plants. B) Relative expression of the selected IMSPs in inoculated $N$. megalosiphon plants at $0,1,3$, and 7 dpi with Ppn. Real-time PCR was used to measure the relative expression of each transcript levels of the genes, as compared to the constitutively expressed 26S rRNA gene as an endogenous control. C) Relative expression of the selected IMSP (Tag 49066) in leaves, stem and roots from inoculated $N$. megalosiphon plants at $0,1,3$, and 7 dpi with Ppn. The 26S rRNA gene was used as an endogenous control. Bars represent mean values $(N=5 ; \pm \mathrm{SD})$.

\subsection{Functional characterization of NmIMSP}

Inoculation with the TRV-based constructs containing a PDS fragment resulted in extensive bleaching that covered all parts of a leaf's lamina and spread systemically toward younger tissues of the inoculated leaf. This was confirmed by subsequent real time PCR analysis to monitor the expression of the two genes encoding the $P D S$ and NmIMSP as the plants showed significantly lowered transcript levels. Additionally, after disease susceptibility testing, plants were tested for transcript levels and only those plants showing significantly lowered transcript levels were taken into account 
A

\begin{tabular}{|c|c|c|}
\hline IMSP $\mathrm{Nm}$ & & \\
\hline$\times 67076$. & $1 \mathrm{Nt}$ & \\
\hline 203199 & $N t$ & \\
\hline $\begin{array}{r}803198 \\
840416\end{array}$ & & \\
\hline $\mathrm{NbS} 000 \mathrm{C}$ & 0367390009.1 & $\mathrm{Nb}$ \\
\hline NbS0001 & 1057290004.1 & $\mathrm{Nb}$ \\
\hline NbSO00 & 3673 g0010.1 & $\mathrm{Nb}$ \\
\hline P16231 & $\underline{S p}$ & \\
\hline P08454 & $\mathrm{st}$ & \\
\hline $853 \times 28$ & & \\
\hline EOWCF2 & st & \\
\hline Q4FE22 & st & \\
\hline Q00783 & st & \\
\hline Q4FE23 & st & \\
\hline Q43648 & st & \\
\hline Q43651 & st & \\
\hline P05118 & s1 & \\
\hline 207459 & st & \\
\hline Q4FE26 & st & \\
\hline Q4FE25 & st & \\
\hline Q3S484 & st & \\
\hline Q3S492 & st & \\
\hline 002753 & Sp & \\
\hline Q4FE24 & st & \\
\hline IMSP $\mathrm{Nr}$ & & \\
\hline$\times 67076$ & $.1 \mathrm{Nt}$ & \\
\hline 803199 & $\mathrm{Nt}$ & \\
\hline Q03198 & $\mathrm{Nt}$ & \\
\hline 840416 & & \\
\hline $\mathrm{NbSOOO}$ & $03673 g 0009.1$ & \\
\hline Nbsooo & 1057290004.1 & $\mathrm{Nb}$ \\
\hline NbSOOO & $03673 g 0010.1$ & $\mathrm{Nb}$ \\
\hline P16231 & Sp & \\
\hline P08454 & $\mathrm{st}$ & \\
\hline $853 \times 28$ & st & \\
\hline EOWCF2 & st & \\
\hline Q4FE22 & st & \\
\hline 000783 & st & \\
\hline Q4FE23 & st & \\
\hline 843648 & st & \\
\hline Q43651 & st & \\
\hline P05118 & s1 & \\
\hline$Q 07459$ & st & \\
\hline Q4FE26 & st & \\
\hline Q4FE25 & st & \\
\hline Q35484 & st & \\
\hline Q3S492 & st & \\
\hline 802753 & Sp & \\
\hline Q4FE24 & st & \\
\hline
\end{tabular}

IMSP Nm

X67076.1 Nt

Q03199 Nt

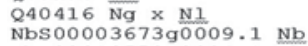

$\mathrm{NbS} 00010572 \mathrm{~g} 0004.1 \mathrm{Nb}$

Nbs00003673g0010.1 Nb

P16231 Sp

P08454 St

EOWCF2 St

Q4FE22 St

800783 St

Q43648 St

$\begin{array}{ll}\text { Q43651 } & \text { St } \\ \text { P05118 } & \text { Sl }\end{array}$

P05118 SI
007459

Q07459 St
Q4FE26 St

Q4FE25 St

Q3S484 St

QOZ7S3 SP
B

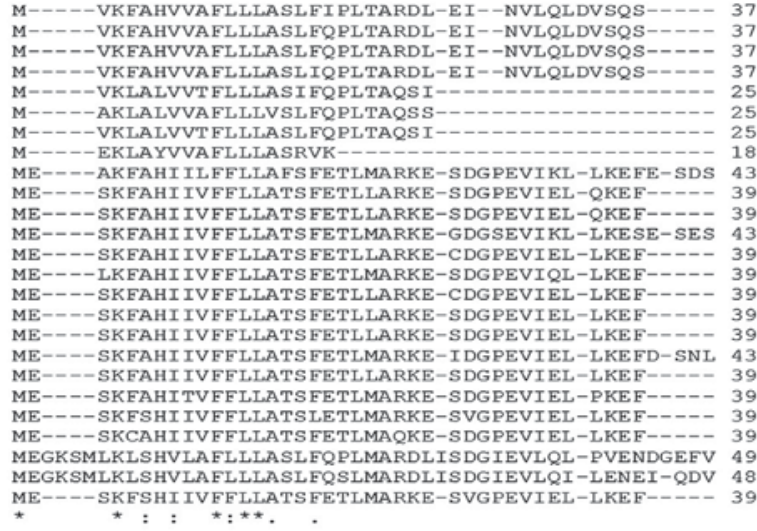

GCPGVTKERWPELLGT PAKFAMAIIQKEAPKLTNVQTVLNGTAVTEDLRC 87 GCPGVTKERWPELLGTPAKFAMQIIQKENPKLTNVQTVLNGTPVTEDLRC 87 GCPGVTKERWPELLGTPAKFAMQIIOKENPKLTNVQTVNGTPVTEDLRC 87 CPGVKKETWPEITGVPAKIARETIOKENSKLTNVPSVINGS PVTQDIRC 74

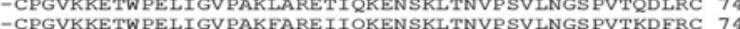
-CPEVKKETWPELIGVPAKFAREIIOKENSKLTNVVSVVNGCGVTKDLRC 74 -KDTWPELLGVPAKLARETIOKEEAKLTNVQNVLNGRFVTODFRC 62 RCKG--KQFW PELIGV PAL YAKG IIEKENPSITN IPILLNGS PVTKDFRC 91 ECNG--KQRWPELIGVPTKLAKGIIEKENSLITNVQILLNGSPVTMDYRC 87 ECNG--KQRWPELIGVPTKLAKGIIEKENSLITNVQILLNGSPVIMDYRC 87 WCKG--KQFWPELIGVPTKLAKEIIEKENPSINDVPIILNGTPVPADFRC 91 CNG-ORWELIGVPKAKGIENENLIADVIIUNGSPADSC 87 CCNG--KORWPGIIGVPAOYAKGIIEKENTI IADVQIIINGSPVTADESC 87 ECNG--KOFW PELIGVPTKLAKE I IEKENSLINNVQILLNGS PVTMDYRC 87 ECNG--KQFWPELIGVPTKLAKEIIEKENSLINNVQILLNGS PVTMDYRC 87 MCEG--KQMWPELIGVPTKLAKEIIEKENPSITNIPILLSGSPITLDYLC 91 ECNG--KQFWPELIGVPTKLAKE IIEKENSLINNVQILLNGSPVAMDYRC 87 CCKG--KLQWPELIGVPTKLAKEIIEKENSLITNVQILLNGSPVTLDFSC 87 CNG-KLWPELIGEPTKLAKEIIEKENSLITNVQILENGSPVTKDFSC 87 FCPG--KOSWPEIVGKSAGYAKOVIEKENSTVHEVKLIEPGMPKPINYVC 97 LCPG--KQSWPELVGKPAEYAKKIIEKENPIAHDIRVLFPGMIRPSNYYC 96 QCNG--KLSWPELIGVPTKLAKEIIEKENSLITNVQILLNGSPVTKDFSC 87

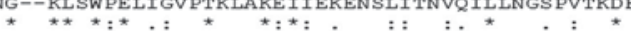

NRVRLFVNVLDFLVQTPQVG 107 NRVRLFVNVLDFVVQTPQVG 107 NRVRLFVAVLDETVOTPOIG 107 DRVRLFVNLIDIVVOIPRVG 94 DRVRLFVNVLDIVVQIPRVG 94 DRVRLFVSVLDFVVQIPRVG 94 DRVRLWVNVLDFVVQTPRVG 82 DRVRLFVNILGDVVQTPRVT 111 NRVRLFDNILGDVVQI PRVA 107 NRVRLEDNILGDVVOIPRVA 111 NRVRIAVNIIDYAVSMPVVG 1107 DRVRLFDNILGYVVDI PVVG 107 NRVRIAVNILDYAVSMPVVG 107 NRVRLFDNILGSVVQIPRVA 107 NRVRLFDNILGDVVQIPRVA 107 DRVRLFDNILGFUVMMPTT 11 NRVRLFDNILGSVVQI PRVA 107 NRVRIFDNIIGDVYEMPVYR 107 DRVRLEDNILGAVVOI PVVG 107 GRVFLVVNFKLVVOVTPSMG 117 GRVFLVVDWEAIVKITPIMG 116 IEFVF-------LITFWVML 100

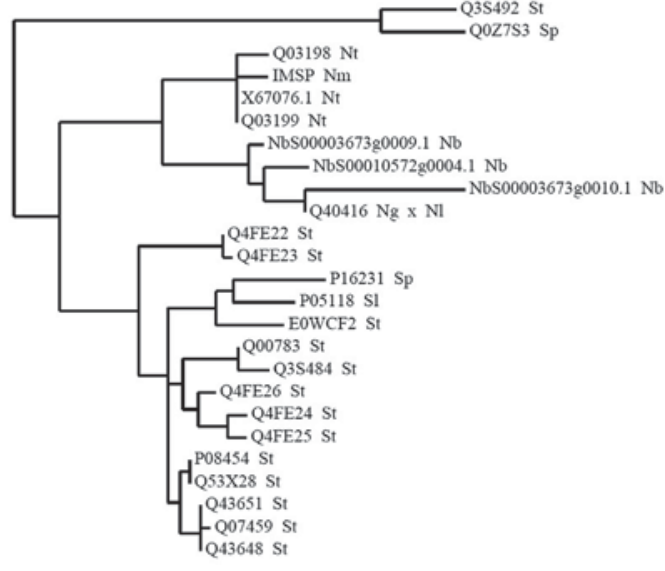

Fig. 2. A) Comparison of the putative sequence of IMSP and those of other Solanaceae protease inhibitors. The sequence alignment was performed with CLUSTAL X software [31]. B) Phylogenetic tree of IMSP with other representative members of Solanaceae protease inhibitors. The phylogenetic tree was generated using the Neighbour Joining method [27] (MEGA 4.0 (http://www.megasoftware.net)) using the same Solanaceae protease inhibitors sequences from the alignment represented above. All the sequences are coded by their accession number followed by the abbreviated name of plant species. Classifiers are as follows: Ng: Nicotiana glauca, Nl: Nicotiana langsdorffii, Nt: Nicotiana tabacum, Nb: Nicotiana benthamiana, Nm: Nicotiana megalosiphon, Sl: Solanum lycopersicum, Sp: Solanum peruvianum, Sp: Solanum phureja, St: Solanum tuberosum.

(Supplementary Table 2). For these plants it was shown that silencing of the NmIMSP transcripts compromised the resistance to P. parasitica var. nicotianae, which demonstrates that the function of this gene is required for resistance to P. parasitica var. nicotianae. However, the disease symptoms were less severe than in the susceptible control (Table 3 ).

Based on the DNA sequence of N. megalosiphon IMSP gene, pairs of primers were designed to clone NmIMSP in the PVX vector (Fig. 3A). Relative expression of NmIMSP mRNA was examined by quantitative RT-PCR in fifty individual plants agro-infiltrated with PVX::NmIMSP vector, in order to select the best expressors of NmIMSP at 15 days post-agro-infiltration, prior to pathogen inoculation. Several $N$. benthamiana plants expressing NmIMSP grown under greenhouse conditions displayed different expression levels of the NmIMSP cDNA. Twenty plants expressing NmIMSP gene with the highest relative expression were selected for disease resistance assays under greenhouse conditions. The expression of NmIMSP gene in PVX::GFP-treated and wild type plants showed basal expression compared with plants over-expressing NmIMSP gene, where the relative expression was higher at 15 days postagro-infiltration (Fig. 3B).

Plants expressing NmIMSP, PVX::GFP and wild type plants were inoculated with the oomycete pathogens $P$. parasitica var. nicotianae and $P$. hyoscyami f. sp. tabacina, respectively. At five days after 
Table 3

Characterization of disease severity of $P$. parasitica var. nicotianae in Nicotiana megalosiphon upon VIGS treatment for NmIMSP gene, one week post inoculation as mean of stem disease rating.

\begin{tabular}{llll}
\hline Stem disease rating $^{\mathrm{a}}$ & & & \\
\hline Non-silenced & pTV:NmPDS & pTV:NmIMSP & $\begin{array}{l}\text { N. tabacum cv. } \\
\text { N. megalosiphon }\end{array}$ \\
1 & 1 & $3.2 \pm 0.1$ & $9.8 \pm 0.1$ \\
\hline
\end{tabular}

a Values are the mean of 15 replicates and \pm represents SD. As control the susceptible N. tabacum cv. 'Sumatra' was included. Development of stem lesions (Stem disease rating) was evaluated using a linear scale of $1-10$, where 1 was no disease and 10 was a dead plant according to Csinos [6].

inoculation slight disease symptoms produced by $P$. parasitica var. nicotianae appeared on the stems in wild type and PVX::GFP plants whereas no symptoms were detected at this stage on the assayed plants expressing NmIMSP gene. However, 10 days after infection severe disease symptoms such as leaf wilting and stem rot were observed in all of the wild type and PVX::GFP (Fig. 4A). The plants expressing NmIMSPgene revealed a low stem disease rating compared with the control plants (Fig. 4C).

Plants expressing NmIMSP gene inoculated with $P$. hyoscyami f. sp. tabacina showed a high resistance to this pathogen. The plants expressing NmIMSP gene remained without typically localized lesions on the leaves at 10 days after infection, while the wild type and PVX::GFP plants showed the severe disease symptoms during the same period (Fig. 4B). The number of the lesions per leaf was higher in the wild type and PVX::GFP plants compared with the plants expressing the NmIMSP gene (Fig. 4D).

\section{Discussion}

The proteinase inhibitors are widespread in plant tissues and highly active to various proteinases from insects, bacteria, and fungi. The inhibitors are proteins that interact with proteinases and suppress their proteolytic activity. In general, plant IMSPs possesses potent and broad-spectrum growth-inhibitory activity against plant pathogens $[15,26]$.

In this study, we exploited the SuperSAGE technique [22] to identify up-regulated genes during $N$. megalosiphon $-P$. parasitica var. nicotianae interaction with focus on genes coding for inhibitors of microbial serine proteinase. SuperSAGE allowed the identification of transcripts of four genes for inhibitors of microbial serine proteinase that were induced during the interaction. Among them, a cDNA encoding an inhibitor of microbial serine proteinase, designated as NmIMSP, was highly induced and associated with defense of $N$. megalosiphon to $P$. parasitica var. nicotianae. Herewith, the expression of NmIMSP gene was higher in leaves and constantly in the time-course. For that reason, we select only this gene for further analyses.

The observation that VIGS of the NmIMSP gene compromises $P$. parasitica var. nicotianae resistance in $N$. megalosiphon indicates the importance of this gene in the defense against this pathogen. Although, we didn't observe a complete susceptibility, the $N$. megalosiphon species was affected by the pathogen. Another, strong evidence supporting the function of NmIMSP in plant defense derives from the enhanced resistance of $N$. benthamiana transiently expressing NmIMSP gene against $P$. parasitica var. nicotianae and $P$. hyoscyami f. sp. tabacina, respectively, as compared to wild type or PVX::GFP-infected plants under greenhouse conditions. Here, we showed for the first time the function of an IMSP gene isolated from Nicotiana species against two important oomycetes.

Interestingly, phylogeny studies including a collection of 25 proteins showed that NmIMSP belongs to a subgroup of Nicotiana IMSPs. Specifically, the NmIMSP had a high homology with members of $N$. tabacum IMSPs, including an IMSP (accession number: X67076.1) induced during tobacco mosaic virus $-N$. tabacum $\mathrm{cv}$. Samsun NN [9]. Curiously, the N. tabacum cv. Samsun NN and $N$. benthamiana plants are highly susceptible to $P$. parasitica var. nicotianae and $P$. hyoscyami f. sp. tabacina. The few amino acid differences between the Nicotiana IMSPs members are probably not the key to provide enhanced resistance in the susceptible $N$. benthamiana against two oomycete pathogens. Probably, the

A

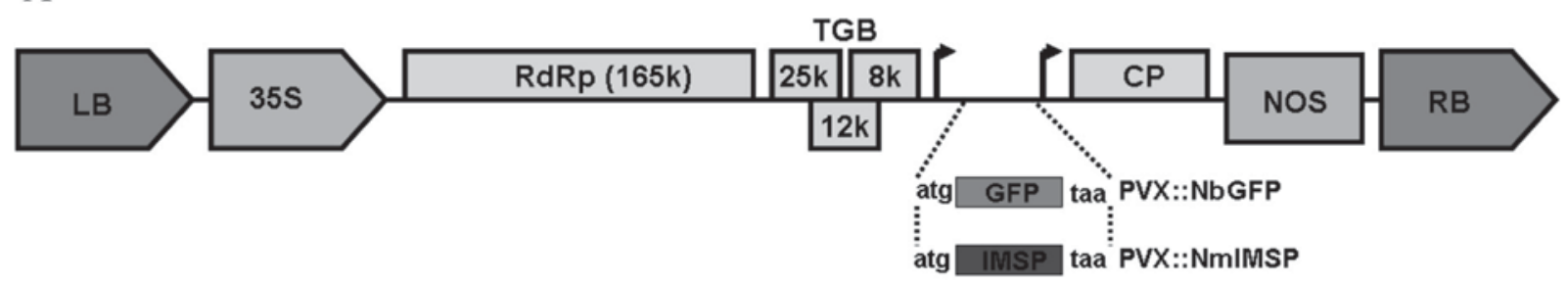

B

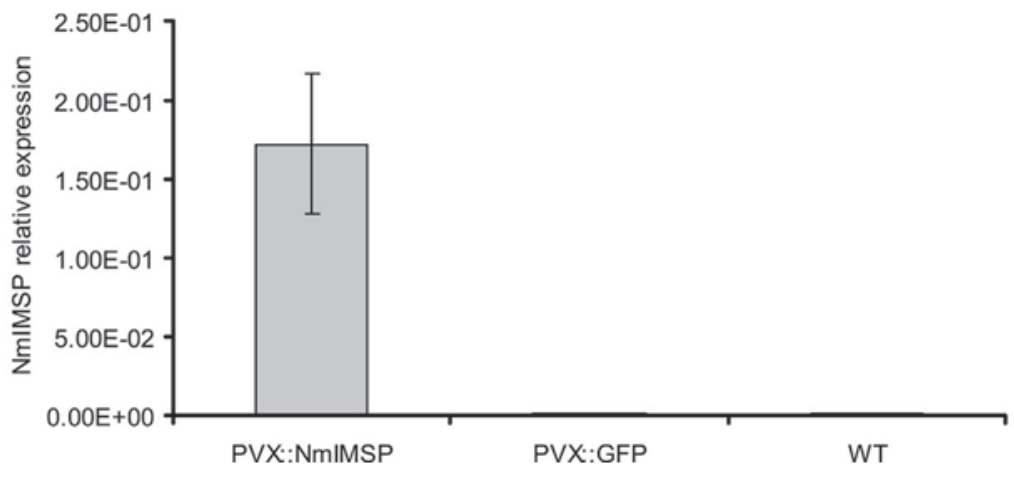

Fig. 3. Transient expression of NmIMSP gene in N. benthamiana plants. Leaves of $N$. benthamiana plants were infiltrated with A. tumefaciens carrying pGR106::NmIMSP. A) Schematic representation of a PVX vector and the Nicotiana megalosiphon full-length IMSP CDNAs. B) Real time-PCR from NmIMSP relative expression in $N$. benthamiana plants at 15 dpi. $N=5$; \pm SD. 
A
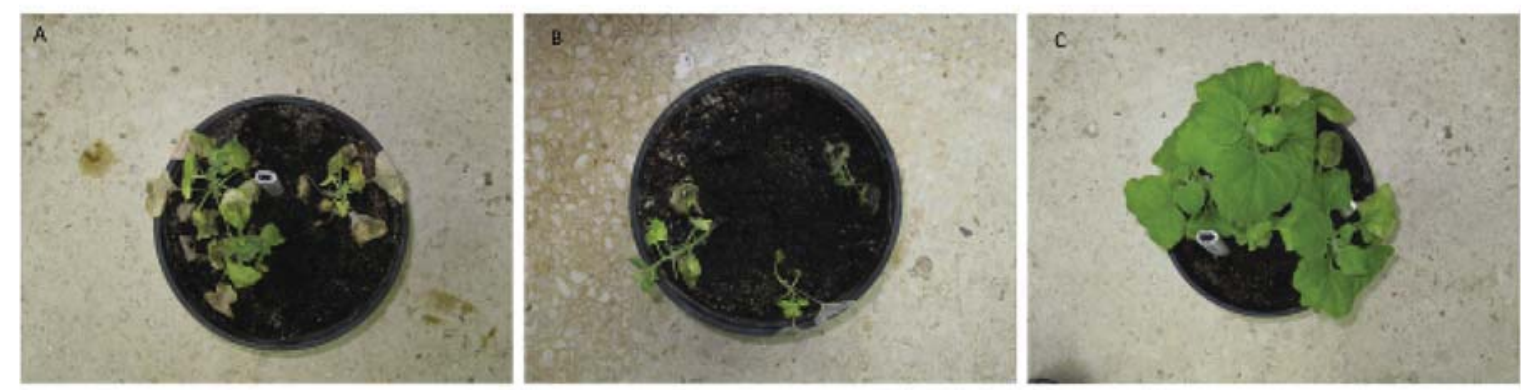

B
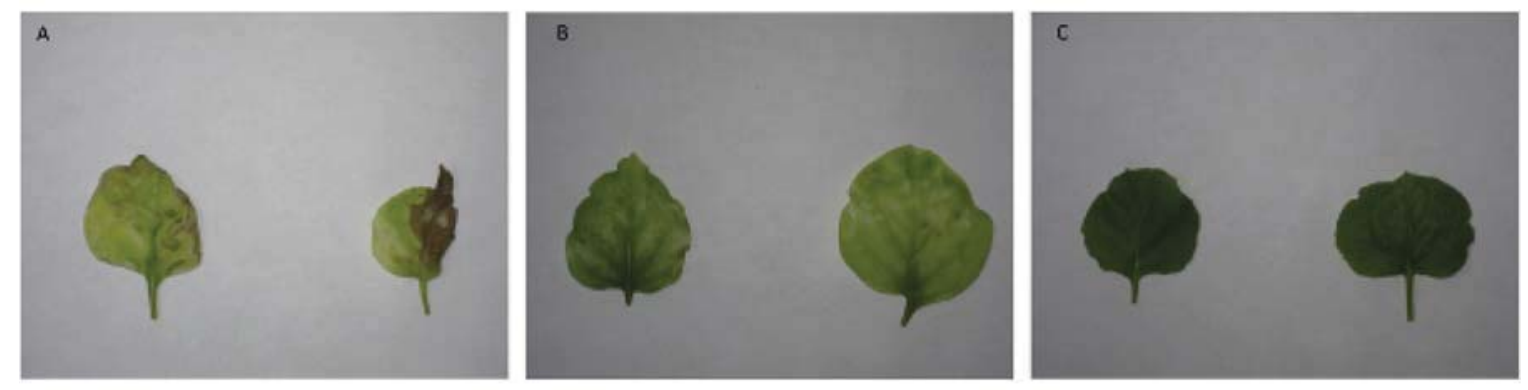

C
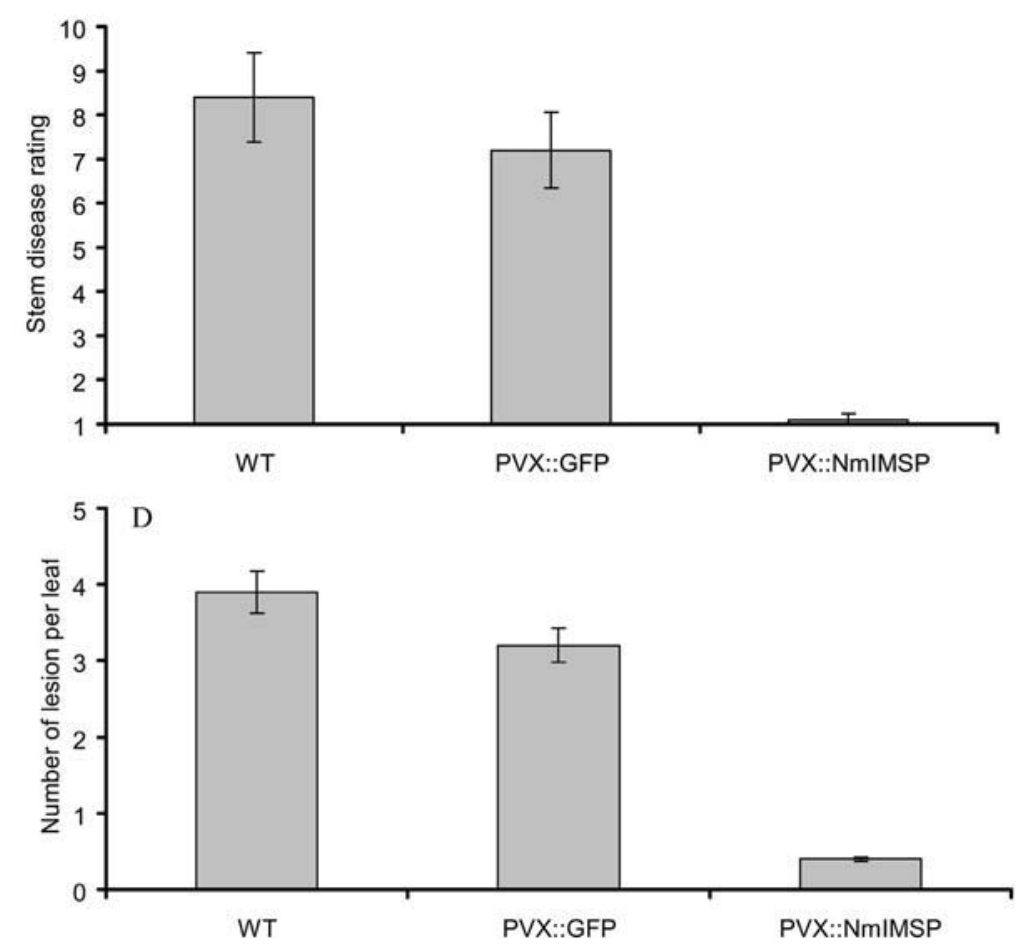

Fig. 4. Greenhouse evaluation of $N$. benthamiana plants expressing the NmIMSP gene inoculated with $P p n$ and $P$. hyoscyami f. sp. tabacina. Phenotype of wild type and N. benthamiana plants expressing the NmIMSP interacting with Ppn (A) and P. hyoscyami f. sp. tabacina at 10 dpi (B), respectively. A) PVX::GFP, B) wild type, C) PVX::NmIMSP. Quantitative evaluation of the $N$. benthamiana disease resistance to $P p n$ (C) and P. hyoscyami f. sp. tabacina (D). Development of stem lesions was evaluated using a linear scale of 110, where 1 was no disease and 10 was a dead plant [6]. The number of lesion was determined according to Borrás-Hidalgo et al. [3] and these are a representative leaf from several assays and experiments. Bars represent mean values $(N=50 ; \pm \mathrm{SE})$. 
expression of the IMSPs present in N. tabacum cv. Samsun NN and $N$. benthamiana plants is not enough or delayed to defeat the pathogens. Therefore, the overexpression of the IMSPs from these species could confer high protection against $P$. parasitica var. nicotianae and $P$. hyoscyami f. sp. tabacina, respectively.

The important role played by IMSP proteins in plant defense has been well documented $[7,15,33,18,23,30,5,11,34$.$] . Some studies$ showed the effect of inhibitors on plant pathogen proteinases under in vitro condition [14,17]. For example, trypsin inhibitors from buckwheat seeds suppressed spore germination and mycelium growth in phytopathogenic fungi Alternaria alternata, Fusarium oxysporum and Rhizoctonia solani, respectively $[7,8,16]$. Moreover, chymotrypsin inhibitors from potato tubers suppressed the growth and development of $P$. infestans $[35,36,38]$. Herewith, cysteine protease inhibitor from pearl millet (Pennisetum glaucum) inhibits growth of many pathogenic fungi, including Trichoderma reesei and a pearl millet cysteine protease inhibitor has been found to possess anti-fungal activity [14].

A potential application of plant protease inhibitors is their use as biotechnological proteins by stable transformation of crops to fight against pathogens. Transgenic plants have been obtained and their partial resistance against pathogens has been tested [28]. Numerous reports had underlined the potential of plant protease inhibitors for the development of pathogen-resistant transgenic crops $[2,11,28,29]$.

In conclusion, the NmIMSP gene identified here appears to be involved in the defense response of N. megalosiphon to P. parasitica var. nicotianae. This gene seems to be important for defense against P. parasitica var. nicotianae and also against $P$. hyoscyami f. sp. tabacina and might be exploited in strategies to develop durable resistance in cultivated tobacco plants through biotechnological approaches.

\section{Appendix A. Supplementary data}

\section{Supplementary data related to this article can be found}

\section{References}

[1] Altschul SF, Madden TL, Schaffer AA, Zhang JH, Zhang Z, Miller W, et al. Gapped BLAST and PSIBLAST: a new generation of protein database search programs. Nucleic Acids Res 1997;25:3389-402.

[2] Benchabane M, Schlüter U, Vorster J, Goulet MC, Michaud D. Plant cystatins. Biochimie 2010;92:1657-66.

[3] Borrás-Hidalgo O, Thomma BPHJ, Collazo C, Chacon O, Borroto CJ, Ayra C, et al. EIL2 transcription factor and glutathione synthetase are required for defense of tobacco against tobacco blue mold. Mol Plant Microbe Interact 2006;19: 399-406.

[4] Chacon O, Hernandez I, Portieles R, Lopez Y, Pujol M, Borrás-Hidalgo O. Identification of defense-related genes in tobacco responding to black shank disease. Plant Sci 2009;177:175-80.

[5] Chen ZY, Brown RL, Lax AR, Cleveland TE, Russin JS. Inhibition of plant pathogenic fungi by a corn trypsin inhibitor overexpressed in Escherichia coli. Appl Environ Microbiol 1999;65:1320-4.

[6] Csinos AS. Stem and root resistance to tobacco black shank. Plant Dis 1999;83: 777-80.

[7] Dunaevsky YE, Elpidina EN, Vinokurov KS, Belozersky MA. Protease inhibitors in improvement of plant resistance to pathogens and insects. Mol Biol 2005;39:608-13.

[8] Dunaevsky YE, Gladysheva IP, Pavlukova EB, Beliakova GA, Gladyshev DP, Papisova AI, et al. The anionic protease inhibitor BWI-1 from buckwheat seeds. Kinetic properties and possible biological role. Plant Physiol 1997:101:483-8.

[9] Geoffroy P, Legrand M, Fritig B. Isolation and characterization of a proteinaceous inhibitor of microbial proteinase induced during hypersensitive reaction of tobacco to Tobacco Mosaic Virus. Mol Plant Microbe Interact 1990;3:327-33.

[11] Haq SK, Atif SM, Khan RH. Protein proteinase inhibitor genes in combat against insects, pests, and pathogens: natural and engineered phytoprotection. Arch Biochem Biophys 2004;431:145-59.

[12] Hellens RP, Edwards AE, Leyland NR, Bean S, Mullineaux MP. pGreen: a versatile and flexible binary Ti vector for Agrobacterium mediated plant transformation. Plant Mol Biol 2000;42:819-32.

[13] Jones L, Hamilton AJ, Voinnet O, Thomas CL, Maule AJ, Baulcombe DC. RNADNA interactions and DNA methylation in post-transcriptional gene silencing. Plant Cell 1999;11:2291-301.

[14] Joshi BN, Sainani MN, Bastawade KB, Gupta VS, Ranjekar PK. Cysteine protease inhibitor from pearl millet: a new class of antifungal protein. Biochem Biophys Res Commun 1998;246:382-7.

[15] Kim JY, Park SC, Hwang I, Cheong H, Nah JW, Hahm KS, et al. Protease inhibitors from plants with antimicrobial activity. Int J Mol Sci 2009;10: 2860-72.

[16] Kim JY, Park SC, Kim MH, Lim HT, Park Y, Hahm KS. Antimicrobial activity studies on a trypsin-chymotrypsin protease inhibitor obtained from potato. Biochem Biophys Res Commun 2005;330:921-7.

[17] Lorito M, Broadway RM, Hayes CK, Woo SL, Noviello C, Williams DL, et al Proteinase inhibitors from plants as a novel class of fungicides. Mol Plant Microbe Interact 1994; 7:525-7.

[18] Lu R, Malcuit I, Moffett P, Ruiz MT, Peart J, Wu AJ, et al. High throughput virus induced gene silencing implicates heat shock protein 90 in plant disease resistance. EMBO J 2003;22:5690-9.

[19] Lu R, Martin-Hernandez AM, Peart JR, Malcuit I, Baulcombe DC. Virus-induced gene silencing in plants. Methods 2003;30:296-303.

[21] Mosolov VV, Loginova MD, Fedurkina NV, Benken II. The biological significance of proteinase inhibitors in plants. Plant Sci Lett 1976;7:77-80.

[22] Matsumura H, Yoshida K, Luo S, Kimura E, Terauchi R. High-throughput SuperSAGE for digital gene expression analysis of multiple samples using next generation sequencing. PLoS ONE 2010;5:1-8.

[23] Pernas M, López-Solanilla E, Sánchez-Monge R, Salcedo G, RodríguezPalenzuela P. Antifungal activity of a plant cystatin. Mol Plant-Microbe Interact 1999;12:624-7.

[25] Ratcliff F, Martin-Hernandez AM, Baulcombe DC. Tobacco rattle virus as a vector for analysis of gene functions by silencing. Plant J 2001;25:237-45.

[26] Ryan CA. Protease inhibitors in plants: genes for improving defenses against insects and pathogens. Annu Rev Phytopathol 1990;28:425-49.

[27] Saitou N, Nei M. The neighbor-joining method: a new method for reconstructing phylogenetic trees. Mol Biol Evol 1987;4:406-25.

[28] Schlüter U, Benchabane M, Munger A, Kiggundu A, Vorster J, Goulet MC, et al. Recombinant protease inhibitors for herbivore pest control: a multitrophic perspective. J Exp Bot 2010;61:4169-83.

[29] Senthilkumar R, Cheng CP, Yeh KW. Genetically pyramiding protease inhibitor genes for dual broad-spectrum resistance against insect and phytopathogens in transgenic tobacco. Plant Biotechnol J 2010;8:65-75.

[30] Soares-Costa A, Beltramini LM, Thiemann OH, Henrique-Silva F. A sugarcane cystatin: recombinant expression, purification, and antifungal activity. Biochem Biophys Res Commun 2002;296:1194-9.

[31] Thompson JD, Gibson TJ, Plewniak F, Jeanmougin F, Higgins DG. The CLUSTAL X windows interface: flexible strategies for multiple sequence alignment aided by quality analysis tools. Nucleic Acids Res 1997;25: 4876-82.

[32] Tian M, Kamoun S. A two disulfide bridge Kazal domain from Phytophthora exhibits stable inhibitory activity against serine proteases of the subtilisin family. BMC Biochem 2005;6:15

[33] Valdes-Rodriguez S, Cedro-Tanda A, Aguilar-Hernandez V, Cortes-Onofre E, Blanco-Labra A, Guerrero-Rangel A. Recombinant amaranth cystatin (AhCPI) inhibits the growth of phytopathogenic fungi. Plant Physiol Biochem 2010;48: 469-75.

[34] Valueva TA, Mosolov VV. Role of inhibitors of proteolytic enzymes in plant defense against phytopathogenic microorganisms. Biochemistry 2004;69: 1305-9.

[35] Valueva TA, Revina TA, Gvozdeva EL, Gerasimova NG, Ozeretskovskaya OL. Role of proteinase inhibitors in potato protection. Bioorg Khim 2003;29:499-504.

[36] Valueva TA, Revina TA, Kladnitskaya GV, Mosolov VV. Kunitz-type proteinase inhibitors from intact and Phytophthora infected potato tuber. FEBS Lett 1998;426:131-4.

[37] Vernekar JV, Tanksale AM, Ghatge MS, Deshpande VV. Novel bifunctional alkaline protease inhibitor: protease inhibitory activity as the biochemical basis of antifyngal activity. Biophys Res Commun 2001;285:1018-24.

[38] Woloshuk CP, Meulenhoff JS, Sela-Buurlage M, van den Elzen PJ, Cornelissen BJ. Pathogen-induced proteins with inhibitory activity toward Phytophthora infestans. Plant Cell 1991;3:619-28. 